\title{
Ethical Issues in the Design and Implementation of Population Health Programs
}

\author{
Matthew DeCamp, $\mathrm{MD}, \mathrm{PhD}^{7}$, Daniel Pomerantz, MD, $\mathrm{MPH}^{2}$, Kamala Cotts, $\mathrm{MD}^{3}$, \\ Elizabeth Dzeng, MD, PhD, MPH ${ }^{4}$, Neil Farber, $M D^{5}$, Lisa Lehmann, MD, PhD, MSc ${ }^{6,7}$, \\ P. Preston Reynolds, $M D, P h D^{8}$, Lois Snyder Sulmasy, $\mathrm{JD}^{9}$, and Jon Tillourt, $M D, M P H^{10}$
}

\begin{abstract}
${ }^{1}$ Berman Institute of Bioethics and Division of General Internal Medicine, Johns Hopkins University, Baltimore, MD, USA; ${ }^{2}$ Albert Einstein College of Medicine and Montefiore New Rochelle Hospital, New Rochelle, NY, USA; ${ }^{3}$ Section of General Internal Medicine, University of Chicago, Chicago, IL, USA; ${ }^{4}$ Division of Hospital Medicine and Social and Behavioral Sciences, University of California - San Franciso, San Francisco, CA, USA; ${ }^{5}$ Division of General Internal Medicine, University of California - San Diego, San Diego, CA, USA; ${ }^{6}$ National Center for Ethics in Health Care, U.S. Department of Veterans Affairs, Washington, DC, USA; ${ }^{7}$ Harvard Medical School and T.H. Chan School of Public Health, Harvard University, Boston, MA, USA; ${ }^{8}$ Division of General, Geriatric, Palliative and Hospital Medicine, University of Virginia, Charlottesville, VA, USA; ${ }^{9}$ Center for Ethics and Professionalism, American College of Physicians, Philadephia, PA, USA; ${ }^{10}$ Divisions of General Internal Medicine, Health Care Policy \& Research, and the Biomedical Ethics Research Program, Mayo Clinic, Rochester, MN, USA.
\end{abstract}

Spurred on by recent health care reforms and the Triple Aim's goals of improving population health outcomes, reducing health care costs, and improving the patient experience of care, emphasis on population health is increasing throughout medicine. Population health has the potential to improve patient care and health outcomes for individual patients. However, specific population health activities may not be in every patient's best interest in every circumstance, which can create ethical tensions for individual physicians and other health care professionals. Because individual medical professionals remain committed primarily to the best interests of individual patients, physicians have a unique role to play in ensuring population health supports this ethical obligation. Using widely recognized principles of medical ethics-nonmaleficence/beneficence, respect for persons, and justice-this article describes the ethical issues that may arise in contemporary population health programs and how to manage them. Attending to these principles will improve the design and implementation of population health programs and help maintain trust in the medical profession.

J Gen Intern Med 33(3):370-5

DOI: $10.1007 / \mathrm{s} 11606-017-4234-4$

(c) The Author(s) 2017. This article is an open access publication

P opulation health, and academic medicine's role in it, is not new. ${ }^{1,2}$ However, it is receiving increased attention. The Triple Aim's goals of improved population health, reduced health care costs, and an improved patient experience of care motivate health system reform. ${ }^{3}$ Other examples include

Received June 21, 2017

Revised October 27, 2017

Accepted November 8, 2017

Published online December 18, 2017 emphasis on population health from national bodies, ${ }^{4}$ efforts to improve quality measures, ${ }^{5-7}$ and changes to health care financing (e.g., value-based payments). ${ }^{8-10}$ The Triple Aim may have originated in the United States out of concern for rising health care costs, poorer than expected health outcomes, and a historical absence of focus on population health. However, many of its associated concepts, including the need to reduce health care costs and achieve higher value care, apply to medical practice globally. Many physicians now practice in settings where population health programs affect how care is delivered.

The Institute of Medicine has defined population health as "the health outcomes of a group of individuals, including the distribution of such outcomes within the group."11, 12 Including health equity (i.e., the distribution of health outcomes within the group) in the definition of population health signifies that justice and health disparities are essential considerations, not afterthoughts. In practice, population health is best understood by analyzing the design and implementation of the discrete population health programs (PHPs) undertaken by health care organizations and others for its sake.

PHPs have the potential to improve the health of individuals. Efforts to improve hypertension screening within a population, for example, could result in better treatment of individuals' hypertension and reduce cardiovascular morbidity and mortality for individuals and the group. Similarly, when PHPs focus on achieving important group outcomes (e.g., hemoglobin A1C targets), many individualsmay benefit.

These potential benefits do not eliminate the need to consider ethical concerns. Proponents of the Triple Aim recognized that achieving the utilitarian (or "greatest good for the greatest number") goals of the Triple Aim could be constrained by non-utilitarian principles. ${ }^{3}$ Advocates of population health acknowledge that, while good for most patients, most of the time, population health programs may not be in the best interest of every individual in every circumstance. ${ }^{13,14}$ 
Physicians practicing within PHPs may face ethical tensions regarding their commitment to individual patients and the broader population. ${ }^{15}$ Population health can push physicians toward traditional public health ethics (where decisions are made with primary concern for large groups of people) and away from clinical ethics (where the decision-making locus is the patient-physician relationship, concerned primarily with individual patient welfare; Table 1).

Because physicians' primary ethical commitment remains to individual patients, ${ }^{16-18}$ physicians have unique roles and obligations regarding population health program implementation. This responsibility is two-fold: first and primarily to fulfill their ethical commitments to the individual patient when practicing under PHPs and secondarily to advocate that health care systems and organizations design and implement PHPs that support these commitments. A prior Society of General Internal Medicine Ethics Committee analysis examined ethical tensions in performance measurement in the context of payfor-performance programs. ${ }^{19}$ Incentives, financial or non-financial, ${ }^{20}$ add an important ethical dimension to performance measurement. Whether or not costs or incentives are directly involved, however, ethical issues may arise in PHPs that deserve examination. Here we describe these issues and suggest how they might be managed.

\section{ETHICAL ISSUES IN PHPS}

Widely recognized ethical principles - non-maleficence (do no harm) and beneficence (acting in patients' best interests), respect for persons, and justice - can help identify the ethical concerns that could arise in the design and implementation of PHPs (Table 2).

\section{Non-maleficence and Beneficence}

Physicians play important public health roles, such as mandatory reporting of certain infectious diseases, and have societal obligations, such as antibiotic stewardship and advocating for health care reform. However, the physician's primary ethical obligations are to focus on promoting the best interests of individual patients. Nonmaleficence requires that physicians ensure PHPs cause no harm to patients. Beneficence requires physicians to support PHPs that actually benefit patients.

In practice, the lines between harmful, non-beneficial, and beneficial effects of PHPs for individual patients may blur. PHPs could improve a population's overall health while resulting in unintended non-beneficial or even harmful individual consequences. For instance, implementing a standard colorectal cancer screening metric with an age cutoff of 75 years - as might be done with an electronic health record pop-up reminder-appears to have been associated with underscreening of healthy individuals over age 75 and overscreening of unhealthy individuals under age $75 .{ }^{21}$ Unintentionally, a metric appeared to discourage appropriately individualized clinical decision-making.

Thus, standard recommendations applied rigidly to groups for average benefit may introduce ethical tensions for physicians caring for unique patients. Physicians should support system defaults that apply standard recommendations, but that application must leave space for individualized risk-benefit determination. It should not result in ordering a test to merely "meet the metric" or not ordering a test merely because the metric does not include it. ${ }^{22}$ It might also allow individual patients to choose to participate in a PHP even if they might not individually benefit, assuming that choice is free and informed (e.g., a patient might choose to participate in a

Table 1 How Population Health May Place Physicians in a Zone of Ambiguity Regarding Their Roles

\begin{tabular}{|c|c|c|c|}
\hline & $\begin{array}{l}\text { Public } \\
\text { health ethics }\end{array}$ & $\begin{array}{l}\text { Population } \\
\text { health ethics }\end{array}$ & $\begin{array}{l}\text { Clinical medical } \\
\text { ethics }\end{array}$ \\
\hline Unit of concern & $\begin{array}{l}\text { Large groups, frequently defined } \\
\text { in part by formal city/state/ } \\
\text { regional/national boundaries }\end{array}$ & $\begin{array}{l}\text { Groups of people, usually defined by where } \\
\text { care is received, local geography, and/or } \\
\text { payer arrangements }\end{array}$ & $\begin{array}{l}\text { An individual person, defined by the } \\
\text { patient-physician relationship }\end{array}$ \\
\hline $\begin{array}{l}\text { Decision-making } \\
\text { locus }\end{array}$ & Public health agency & $\begin{array}{c}\text { Health care organization, system, or payer } \\
\text { Ethical }\end{array}$ & Patient-physician relationship \\
\hline $\begin{array}{l}\text { Primary animating } \\
\text { ethical principle(s) }\end{array}$ & $\begin{array}{l}\text { Group welfare, safety, or } \\
\text { protection from harm }\end{array}$ & & $\begin{array}{l}\text { Protection of individual patient welfare } \\
\text { (i.e., non-maleficence and beneficence) }\end{array}$ \\
\hline Secondary & Liberty rights & Of & Respect for individual autonomy/choice \\
\hline $\begin{array}{l}\text { constraining ethical } \\
\text { principles(s) }\end{array}$ & Equity & & Justice \\
\hline \multirow[t]{3}{*}{$\begin{array}{l}\text { Paradigmatic ethical } \\
\text { issues }\end{array}$} & $\begin{array}{l}\text { - Tension between mandatory } \\
\text { vaccination or quarantine } \\
\text { measures and individual } \\
\text { autonomy/choice }\end{array}$ & $\begin{array}{l}\text { - Tension between improving individual or } \\
\text { group performance measures and patient } \\
\text { choice regarding their health priorities }\end{array}$ & $\begin{array}{l}\text { - Respecting patients' autonomous } \\
\text { choices, even when not in their } \\
\text { "medical" best interests (informed } \\
\text { consent) }\end{array}$ \\
\hline & $\begin{array}{l}\text { - How to determine fair resource } \\
\text { allocation during an epidemic }\end{array}$ & $\begin{array}{l}\text { - Impact of population health activities (e.g., } \\
\text { automated reminders, contact from non-care } \\
\text { team members) on patient trust in physician }\end{array}$ & $\begin{array}{l}\text { - Physicians' obligation to recognize } \\
\text { individual- and system-level biases the } \\
\text { lead to disparities }\end{array}$ \\
\hline & $\begin{array}{l}\text { - Use of behavioral economics to } \\
\text { "nudge" food choices and the } \\
\text { impact on individual choice }\end{array}$ & $\begin{array}{l}\text { - How to appropriately define and respond to } \\
\text { "at risk" patients via predictive analytics } \\
\text { (including their effect on disparities) }\end{array}$ & $\begin{array}{l}\text { - Physician engagement in } \\
\text { shared-decision making and encourage- } \\
\text { ment of healthy behaviors }\end{array}$ \\
\hline
\end{tabular}


Table 2 Examples of Ethical Issues in Population Health Programs (PHPs) with Example Management Strategies

\begin{tabular}{llll}
\hline \hline Ethical questions & $\begin{array}{l}\text { Eon-maleficence and } \\
\text { beneficence }\end{array}$ & Respect for persons & Justice \\
\hline Patient level & $\begin{array}{l}\text { "Is this PHP in my } \\
\text { individual best interest?" }\end{array}$ & $\begin{array}{l}\text { "Does this PHP protect and "Able my choice?" } \\
\text { enabedural the benefits and }\end{array}$ & $\begin{array}{l}\text { "Arrdens of the PHP shared } \\
\text { equally across all } \\
\text { patients?" }\end{array}$
\end{tabular}

Example:

Improving the rate of colorectal cancer

screening in those age

$50-75$ by colonoscopy,

sigmoidoscopy, or FOBT

Example management strategy

\section{Physician-level}

\section{Example:}

Improving A1C control in patients with diabetes using a new default

Diabetes Care Order Set

Example management strategy

\section{Organization-level}

Example:

Reducing hospital readmissions

Example management strategy
Efforts to meet this metric result in unnecessary screening of patients with limited life expectancy as an unitended consequence (e.g., a 74 year old with a terminal illness)

Actively monitor, using EMR data, for evidence of over- and under-screening and take action to prevent it

"Will this PHP enable me to fulfill my obligations of beneficience to my patients?"

The focus on diabetes in EMR clinical decision support distracts a physician from other medical or social issues important to individual patients Evalute for unintended consequences of PHPs, e.g., whether improvement in one area results in lagging performance in others or reduced patient satisfaction in the encounter

"Will this PHP actually improve the care we deliver to patients, not just improve measurement or documenation?"

A health care organization reduces readmissions to its hospital by shifting care to the emergency room or observation status

A readmission reduction program pays careful attention to whether it unintentionally shifted costs when it tracks program outcomes
Rather than allowing for discussion of the risks and benefits of colonoscopy, sigmoidoscopy, or FOBT, FOBT is advocated by the PHP as a way to achieve performance quickly

Present the risks and benefits of possible recommended actions in a balanced way to enable informed choice (not, e.g., encouraging FOBT just to meet the metric quickly)

"Do I still feel free to choose and recommend what I believe best for patients?"

A pre-filled referral order routes patients to a list of preferred endocrinologists, when the physician and patient believe a different endocrinologist would be best Design referral processes to preserve patient-physician shared decision-making (e.g., informing both about the rationale behind the preferred list and allow exceptions)

"Is the PHP implemented in a way that is respectful? For example is is culturally sensitive and respectful of persons?"

A post-discharge home care program is standardized but fails to accommodate patients' social and cultural differences (e.g., related to family involvement in home care)

A medical chart flag for patients at high risk of readmission using predictive analytics is inadvertently stigmatizing

Post-discharge home care programs should be explicitly designed to be respectful of social and cultural differences Careful language should be used to describe "high risk," preferably crafted with patient input and with training of health care professionals regarding its meaning
Electronic outreach messages via the EMR preferentially reach certain groups, reducing the potential beneft for others (those with limited English proficiency or without electronic access) Ensure messaging is equitably accessible for all groups at the time of initial design (lest these groups be left out, once a goal is met)

"Are the benefits and burdens of PHPs equitably distributed among all clinicians?"

Primary care phyicians, compared to specialists, bear more of the burden for meeting the metric (e.g. time in EMR

documentation)

Recognize this extra burden by providing adequate time or personnel resources (or, if applicable, shared savings) that result from these efforts

"Are we giving special concern to our most vulnerable patients?"

In a setting where certain patients most in need decline post-discharge home care, an organization excludes these patients from its denominator when it calculates its success rate

Special attention is given to better understanding why patients decline and developing appropriate ways to reach them
Patients were not involved in the review of the electronic message or its content

Design PHPs with input from patient and family advisory councils (PFACs)

"Were front-line clinicians involved in PHP development?"

A diabetes order set is designed without input from front-line physicians, reducing buy-in (and adherence) to it

Design the PHP with input from the physicians who will use it to improve buy-in, trust, and PHP success

"What structures ensure ongoing engagement of physicians and patients in the design and implementation of PHPs?"

A post-discharge care management program is designed with patient input, but not from patients who will use the program

Ensure that the patient engagement program that informs program design includes patients representative of the enduser group 
population-wide screening program that contributes to organizational population health efforts, even knowing he/she is very low risk and might assume out-of-pocket costs related to screening). Moreover, organizations should develop the capability to monitor for unintended consequences of overuse and underuse. $^{23}$

Beneficence also requires that PHPs support patientphysician relationships, trust, and continuity. PHPs may disrupt trust if patients perceive an overemphasis on certain health conditions (e.g., a focus on diabetes care when the patient is most concerned about other physical or mental health issues) or overly influenced by incentives (e.g., in pay-for-performance ${ }^{19,20}$ or value-based payment contracts). Trust could also be disrupted if, for example, a patient allergic to the influenza vaccine receives an influenza vaccine reminder and questions why the "doctor forgot me."

Alleviating tensions between physicians' obligations to individual patients and population health requires system-level support. $^{24}$ The patient-physician relationship can assist appropriate population health goals, ${ }^{25,}{ }^{26}$ but this must be done with great care. For instance, personalized outreach letters to patients from their personal physicians may be more effective than one from an unknown clinical director. ${ }^{27}$ Because of the power of this relationship and the potential for its disruption, health systems must ensure that physicians are aware of PHPs, involved in their design, and consulted on the content and timing of patient outreach messaging (particularly when messaging includes individual physicians' names).

Patient-centered care requires that organizations choose PHPs that truly meet their patients' needs (whether or not these needs are captured by population health metrics) and build systems that do not erode professionals' capacity to care for patients. ${ }^{28,29}$ Organizations must commit to the full spirit, and not just the letter, of population health goals. For instance, when an organization dedicates a PHP to a screening measure (e.g., screening for fall risk), it should simultaneously commit to developing care processes to prevent falls. Similarly, when an organization seeks to reduce readmissions, it should do so meaningfully - not merely by developing workarounds to avoid readmission penalties. $^{30,31}$

\section{Respect for Persons and Patient Autonomy}

Respect for persons requires protecting a patient's humanity, including the ability to make free and informed choices about care consistent with the patient's personal values. This requires recognizing the physician's clinical judgment in helping patients make these decisions. Informed or shared decision-making - a collaborative, dynamic, and shared process regarding care choices-operationalizes respect for persons. ${ }^{32-34}$ However, individual patients' preferences may not align with the preferred option of a given PHP. After all, sometimes the express purpose of a PHP is to influence choice in favor of a particular outcome ${ }^{35}$ and influence physician behavior. ${ }^{36}$
Colorectal cancer screening is again a useful example. Guidelines acknowledge different risks and benefits of screening modalities, ${ }^{37}$ and population health measures are flexible regarding measure requirements. ${ }^{38}$ In fiscal expedience, PHPs could not only encourage fecal occult blood testing (e.g., by making this the default option in an order set or by encouraging it in an outreach letter) but also actively discourage colonoscopy (e.g., by highlighting its inconvenience or cost). If the choice of screening modality is truly "preference sensitive," doing so may ethically jeopardize patient preferences and individualized clinical judgment. When evidence does not suggest a clearly superior option, it would be more respectful to encourage well-supported and unhurried conversations between physicians and patients (including the use of decision aids, if appropriate) — not stack the deck to favor a particular outcome. $^{39}$

Organizations must design and use PHPs in ways that are evidence-based, align with physician ethical responsibilities, and respect patient preferences and cultural differences. This includes choices related to language, educational materials, and community intervention programs. ${ }^{40}$ For example, postdischarge care programs that accommodate cultural differences are more respectful (and probably more effective at preventing readmissions). ${ }^{41-43}$ In addition, as organizations increasingly use predictive analytics to identify patients at high risk of admission, readmission, or high utilization of health care, respect requires that these analytics and their display are not stigmatizing (e.g., the use of an airplane EMR icon to flag "frequent flyers," a pejorative term for "high cost patients") ${ }^{44}$ and that affected patient populations are involved in analytic design. ${ }^{45}$

\section{Justice}

Both distributive justice (i.e., questions of resource distribution, such as fairly allocating organs for transplantation) and procedural justice (i.e., fair decision processes) must be considered in an ethical analysis of PHPs.

Distributive Justice. Emphasis on a fair distribution of resources and explicit protection for vulnerable individuals is found in principles of medical professionalism, ${ }^{16}$ organizational ethics, ${ }^{46}$ and the definition of population health itself. ${ }^{12}$ This consensus requires PHPs to proactively address distributional inequities in the burdens and benefits programs entail. An intervention could conceivably reach an overall measure target (e.g., a 90\% influenza vaccination rate) without reaching vulnerable, marginalized, or minority groups (e.g., if the $10 \%$ of patients who are unvaccinated includes an overrepresentation of patients in these groups who are especially difficult to reach). Were a PHP to send outreach reminders to patients via an online portal or only in English, it might be an efficient means of outreach but could inadvertently exclude certain patient groups (i.e., those without access to the Internet portal ${ }^{47,48}$ or those with limited English proficiency). Although individual physicians 
cannot be held responsible for this systemic shortcoming, physicians' commitment to justice includes a responsibility to be aware of these potential consequences and advocate for PHPs to proactively tailor interventions and ensure vulnerable, marginalized, or minority groups can share in population health benefits while respecting their right of informed refusal.

Issues of distributive justice are not limited to patients. Because many PHPs focus on primary care, the potential burdens of PHPs in responding to outreach messages, documenting screening, etc., may fall disproportionately on primary care clinicians. ${ }^{49}$ Distributive justice requires health care organizations ensure primary care clinicians have the time, administrative support, and resources to enable them to deliver care to all those in need, including healthy, chronically ill, and disadvantaged populations.

Procedural Justice. Procedural justice means that fair decision processes should govern individual and corporate deliberations. Ethically, it requires creating opportunities to engage patients in their own care and in health care organizational decision-making (e.g., as patient members of organizational quality improvement committees or via patient and family advisory councils, PFACs). ${ }^{50,51}$ Engagement, as desired by the patient, ${ }^{16}$ is therefore part of broader justicebased obligations to create fair decision processes ${ }^{52,53}$ independent of immediate consequences. PHPs should engage patients and clinicians in their design and implementation. This may lead to better-designed programs that may be more effective and promote greater trust in the organization longterm. As hospitals and health systems create PFACs and other means for engagement, they should do so using available resources and recommended practices. ${ }^{54,55}$

\section{CONCLUSION}

Ethical issues that arise in population health are not new. But they may not receive appropriate attention in contemporary fast-paced health care environments where committees and others make decisions regarding population health programming. Physicians play a critical role as individuals and members of a profession when they fuflfill their primary ethical commitment to individual patients, including in the context of population health programs, and advocate that population health programs be consistent with those fundamental ethical commitments.

Acknowledgments: The development of this manuscript was supported by the Society of General Internal Medicine. We wish to acknowledge the members and staff of the SGIM Ethics Committee. The views expressed in this manuscript are the authors' own and do not represent the official policies of SGIM, the American College of Physicians, or the Department of Veterans Affairs.
Corresponding Author: Matthew DeCamp, MD, PhD; Berman Institute of Bioethics and Division of General Internal Medicine Johns Hopkins University, Deering Hall 1809 Ashland Avenue, Baltimore, MD 21205, USA (e-mail: mdecamp1@jhmi.edu).

Compliance with ethical standards: The authors declare that they do not have a conflict of interest.

Open Access This article is distributed under the terms of the Creative Commons Attribution 4.0 International License (http:// creativecommons.org/licenses/by/4.0/), which permits unrestricted use, distribution, and reproduction in any medium, provided you give appropriate credit to the original author(s) and the source, provide a link to the Creative Commons license, and indicate if changes were made.

\section{REFERENCES}

1. White KL, Connelly JE. The medical school's mission and the population's health. Ann Intern Med 1991;115(12):968-72.

2. Gourevitch MN. Population health and the academic medical center: the time is right. Acad Med 2014;89(4):544-49.

3. Berwick DM, Nolan TW, Whittington J. The triple aim: care, health, and cost. Health Aff 2008;27(3):759-69.

4. National Academies of Sciences, Engineering, and Medicine. Advancing the Science to Improve Population Health: Proceedings of a Workshop. Washington, DC: The National Academies Press, 2017. https://doi.org/ $10.17226 / 23541$

5. Institute of Medicine. Vital signs: core metrics for health and health care progress. Washington, DC: The National Academies Press, 2015.

6. Centers for Medicare \& Medicaid Services. CMS Quality Measure Development Plan: Supporting the Transition to the Merit-based Incentive Payment System (MIPS) and Alternative Payment Models (APMs). Baltimore, MD: Centers for Medicare \& Medicaid Services; 2016. Available at: https://www.cms.gov/Medicare/Quality-Initiatives-PatientAssessment-Instruments/Value-BasedPrograms/MACRA-MIPS-andAPMs/MACRA-MIPS-and-APMs.html. Accessed 18 May 2017.

7. Centers for Medicare \& Medicaid Services. Core measures. Available at https://www.cms.gov/Medicare/Quality-initiatives-patient-assessmentinstruments/qualitymeasures/core-measures.html. Accessed 18 May 2017.

8. Schneider EC, Hall CJ. Improve quality, control spending, maintain access - can the merit-based incentive payment system deliver? N Engl J Med 2017;376:708-10.

9. Muhlestein D, McClellan M. Accountable care organizations in 2016: private and public-sector growth and dispersion. 2016. Available at: http://healthaffairs.org/blog/2016/04/21/accountable-care-organizations-in-2016-private-and-public-sector-growth-and-dispersion/. Accessed 19 May 2017.

10. Rajkumar R, Patel A, Murphy $\mathbf{K}$, et al. Maryland's all-payer approach to delivery-system reform. N Engl J Med 2014;370(6):493-95.

11. The National Academies of Sciences, Engineering, Medicine. Working definition of population health. 2013. Available at http:// nationalacademies.org/hmd/ /media/Files/Activity\%20Files / Public Health / Population Health ImprovementRT / Population\%20Health\%20RT\%20Working\%20Definition.pdf. Accessed 19 May 2017.

12. Kindig D, Stoddart G. What is population health? Am J Public Health 2003;93(3):380-83.

13. Sox HC. Resolving the tension between population health and individual health care. JAMA 2013;310(18): 1933-34.

14. Teutsch SM, Chokshi DA, Stine NW, Fielding JE. HALE - unification theory for clinical medicine and population health. Institute of Medicine of the National Academies. 2013.

15. Kaldjian LC. Patient care and population health: goals, roles and costs. J Public Health Res 2014;3(2):311.

16. Snyder L, The American College of Physicians Ethics, Professionalism, and Human Rights Committee. American College of Physicians Ethics Manual: Sixth edition. Ann Intern Med. 2012;156:73-104.

17. American Medical Association. 11.1.2. Physician stewardship of health care resources. Code of medical ethics. June 2016 edition. American Medical Association.

18. ABIM Foundation. American Board of Internal Medicine, ACP-ASIM Foundation, American College of Physicians-American Society of Internal 
Medicine, European Federation of Internal Medicine. Medical professionalism in the new millennium: a physician charter. Ann Intern Med 2002; 136(3):243-46.

19. Wharam JF, Paasche-Orlow MK, Farber NJ, et al. High quality care and ethical pay-for-performance: a Society of General Internal Medicine policy analysis. J Gen Intern Med 2009;24(7):854-59.

20. Snyder L, Neubauer RL, American College of Physicians Ethics, Professionalism and Human Rights Committee. Pay-for-performance principles that promote patient-centered care: an ethics manifesto. Ann Intern Med 2007;147(11):792-794.

21. Saini SD, Vijan S, Schoenfeld P, Powell AA, Moser S, Kerr EA. Role of quality measurement in inappropriate use of screening for colorectal cancer: retrospective cohort study. BMJ 2014;348:g1247.

22. Baker DB, Gaseem A. American College of Physicians' Performance Measurement Committee. Evidence-based performance measures: preventing unintended consequences of quality measurement. Ann Intern Med 2011;155(9):638-640.

23. Walter LC, Davidowitz NP, Heineken PA, Covinsky KE. Pitfalls of converting practice guidelines into quality measures: lessons learned from a VA performance measure. JAMA 2004;291(20):2466-70.

24. Tilburt J, Brody B. Doubly distributing special obligations: what professional practice can learn from parenting. J Med Ethics 2016. https://doi.org/10.1136/medethics-2015-103071.

25. Hodach R. Provider-led population health management. Bloomington: AuthorHouse, 2014.

26. Stead LF, Buitrago D, Preciado N, Sanchez G, Hartmann-Boyce J, Lancaster T. Physician advice for smoking cessation. Cochrane Database Syst Rev 2013;(5):CD000165.

27. Lewis CL, Brenner AT, Griffith JM, Moore CG, Pignone MP. Two controlled trials to determine the effectiveness of a mailed intervention to increase colon cancer screening. N C Med J 2012;73(2):93-8.

28. Povar GJ, Blumen H, Daniel J, et al. Ethics in practice: managed care and the changing health care environment: medicine as a profession managed care ethics working group statement. Ann Intern Med 2004;141(2): 131-6.

29. Davis K, Schoenbaum SC, Audet AM. A 2020 vision of patient centered primary care. J Gen Intern Med 2005;20(10):953-57.

30. Zuckerman RB, Sheingold SH, Orav EJ, Ruhter J, Epstein AM. Readmissions, observation, and the hospital readmissions reduction program. N Engl J Med 2016;374(16): 1543-1551.

31. Woolhandler $\mathbf{S}$, Himmelstein DU. The hospital readmissions reduction program. N Engl J Med 2016;375(5):493.

32. Emanuel EJ, Emanuel LL. Four models of the physician-patient relationship. JAMA 1992;267(16):2221-26.

33. Charles C, Gafni A, Whelan T. Shared decision-making in the medical encounter: what does it mean? (or it takes at least two to tango). Soc Sci Med 1997;44(5):681-692.

34. Elwyn G, Frosch D, Thomson $\mathbf{R}$, et al. Shared decision making: a model for clinical practice. J Gen Intern Med 2012;27(10):1361-7.

35. Kaplan R, Spittel M, David D. Population health: behavioral and social science insights. AHRQ Publication No. 15-0002. Rockville: Agency for Healthcare Research and Quality and Office of Behavioral and Social Sciences Research, National Institutes of Health; 2015

36. Emanuel EJ, Ubel PA, Kessler JB, et al. Using behavioral economics to design physician incentives that deliver high-value care. Ann Intern Med 2016; 164(2):114-19.

37. US Preventive Services Task Force, Bibbins-Domingo K, Grossman DC, Curry SJ, Davidson KW, Epling JW, Jr, et al. Screening for colorectal cancer: US Preventive Services Task Force recommendation statement. JAMA 2016;315(23):2564-75.

38. National Committee for Quality Assurance. NQF \#0034 colorectal cancer screening measure submission and evaluation worksheet. NQF. 2009.

39. Volk RJ, Linder SK, Lopez-Olivo MA, et al. Patient decision aids for colorectal cancer screening: a systematic review and meta-analysis. Am J Prev Med 2016;51(5):779-91.

40. Albert SM. Impact of cultural, social, and community environments on home care. In National Research Council (ed.), The role of human factors in home health care: workshop summary. Washington, DC: The National Academies Press. 2010:247-74.

41. Li WW, Stewart AL, Stotts N, Froelicher ES. Cultural factors associated with antihypertensive medication adherence in Chinese immigrants. J Cardiovasc Nurs 2006;21(5):354-62

42. Davidson PM, Macdonald P, Moser DK, et al. Cultural diversity in heart failure management: findings from the DISCOVER study (part 2). Contemp Nurse 2007;25(1-2):50-61.

43. Betancourt JR, Tan-McGrory A, Kenst KS. Guide to Preventing Readmissions among Racially and Ethnically Diverse Medicare Beneficiaries. Prepared by the Disparities Solutions Center, Mongan Institute for Health Policy at Massachusetts General Hospital. Baltimore, MD Centers for Medicare \& Medicaid Services Office of Minority Health; 2015.

44. Joy M, Clement T, Sisti D. The ethics of behavioral health information technology: frequent flyer icons and implicit bias. JAMA 2016;316(15):1539-40.

45. Cohen IG, Amarasingham R, Shah A, Xie B, Lo B. The legal and ethical concerns that arise from using complex predictive analytics in health care. Health Aff 2014;33(7):1139-47.

46. Pearson SD, Sabin JE, Emanuel EJ. No Margin, No Mission. New York: Oxford; 2003.

47. Smith SG, O'Conor R, Aitken W, Curtis LM, Wolf MS, Goel MS Disparities in registration and use of an online patient portal among older adults: findings from the LitCog cohort. J Am Med Inform Assoc 2015;22(4):888-95.

48. Irizarry T, DeVito Dabbs A, Curran CR. Patient portals and patient engagement: a state of the science review. J Med Internet Res 2015;17(6):e148.

49. Murphy DR, Meyer AN, Russo E, Sittig DF, Wei L, Singh H. The burden of inbox notifications in commercial electronic health records. JAMA Intern Med 2016;176(4):559-60.

50. Carman KL, Dardess P, Maurer $\mathbf{M}$, et al. Patient and family engagement: a framework for understanding the elements and developing interventions and policies. Health Aff 2013;32(2):223-31.

51. Danis M, Solomon M. Providers, payers, the community, and patients are all obliged to get patient activation and engagement ethically right. Health Aff 2013;32(2):401-7.

52. Emanuel EJ. Patient v. population: resolving the ethical dilemmas posed by treating patients as members of populations. In Danis M, Clancy C Churchill LR (Eds.), Ethical dimensions of health policy. New York: Oxford University Press; 2002:227-245.

53. Williamson $\mathbf{L}$. Patient and citizen participation in health: the need for improved ethical support. Am J Bioeth 2014;14(6):4-16.

54. Jeppson ES, Thomas J. Essential allies: families as advisors. Bethesda: Institute for Family-Centered Care. 1994.

55. Agency for Healthcare and Quality, Rockville, MD. Guide to patient and family engagement in hospital quality and safety. 2013. Available at https://www.ahrq.gov/professionals / systems/hospital/ engagingfamilies/guide.html. Accessed 19 May 2017. 